\title{
Vücut-kitle indeksi ile Helicobacter pylori enfeksiyonu arasındaki ilişki: bir vaka kontrol çalışması
}

\author{
The relationship between body-mass index and Helicobacter pylori \\ infection: a case-control study
}

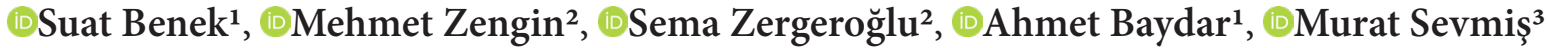 \\ ${ }^{1}$ Tekirdağ Namık Kemal Üniversitesi, Tip Fakültesi, Genel Cerrahi Anabilim Dalı, Tekirdağ, Türkiye \\ ${ }^{2}$ Kırıkkale Üniversitesi, Tıp Fakültesi, Tibbi Patoloji Anabilim Dalı, Kırıkkale, Türkiye \\ ${ }^{3}$ Yeni Yüzyıl Üniversitesi, Tip Fakültesi, Genel Cerrahi Anabilim Dalı, İstanbul, Türkiye
}

Cite this article as/Bu makaleye atıf için: Benek S, Zengin M, Zergeroğlu S, Baydar A, Sevmiș M. Vücut-kitle indeksi ile Helicobacter pylori enfeksiyonu arasındaki ilişki: bir vaka kontrol çalışması. J Med Palliat Care 2021; 2(2): 35-39.

\section{ÖZ}

Amaç: Helicobacter pylori (H. pylori) enfeksiyonu dünya genelinde oldukça yaygın olan enfeksiyonlardan biridir. $H$. pylori ile obezite arasındaki ilişki hakkında literatürde farklı görüşler vardır. Bu çalışmada vücut-kitle indeksi (VKİ) ile H. pylori enfeksiyonu arasındaki ilişkiyi araştırdık.

Gereç ve Yöntem: 2019 yılı içerisinde Tekirdağ Namık Kemal Üniversitesi Tip Fakültesi Hastanesỉnde endoskopik muayeneleri yapılan hastalar arasında kesitsel bir çalışma yapıldı. H. pylori enfeksiyonunun prevalansı biyopsi ile incelendi. VKİ ile H. pylori enfeksiyonu arasındaki ilişki analiz edildi.

Bulgular: Popülasyonumuzdaki olguların \%51,8’i H. pylori enfeksiyonu açısından pozitifti. Histopatolojik incelemede $H$. pylori-pozitif olgularda akut ve kronik inflamasyon bulguları $H$. pylori-negatif olgulara kıyasla daha fazla idi. VKİ'si yüksek olan hastalarda $H$. pylori enfeksiyonu prevalansı VKİ'si düşük olanlara göre daha fazla idi. İstatistiksel analizde VKİ ile H. pylori enfeksiyonu prevalansı arasında anlamlı bir ilişki olduğu görüldü $(\mathrm{p}<0,001)$ ve bu iki parametre arasında pozitif bir doğrusal korelasyon vardı $(\mathrm{r}=0,542)$. Risk faktörleri tek değişkenli olarak incelendiğinde VKİnin $H$. pylori enfeksiyonu açısından anlamlı bir risk faktörü olduğu tespit edildi ( $\mathrm{p}=0,008)$. Çoklu analiz sonuçları ise VKİ’nin $H$. pylori enfeksiyonu açısında bağımsız bir risk faktörü olduğunu ortaya koydu $(\mathrm{OR}=1,32(1,09-3,46), \mathrm{p}=0,025)$.

Sonuç: Bulgularımız VKİ ile H. pylori enfeksiyonu arasında anlamlı bir ilişkili olduğunu ve yüksek VKİ'nin H. pylori enfeksiyonu açısından bağımsız bir risk faktörü olduğunu gösterdi.

Anahtar Kelimeler: Vücut-kitle indeksi, gastrit, Helicobacter pylori, histopatolojik bulgular

\begin{abstract}
Objective: Helicobacter pylori infection is one of the most common infections worldwide. There are different opinions in the literature about the relationship between $H$. pylori and obesity. In this study, we investigated the relationship between body-mass index (BMI) and $H$. pylori infection.

Material and Method: A cross-sectional study was conducted among patients who underwent endoscopic examinations at Tekirdağ Namık Kemal University Faculty of Medicine Hospital in 2019. The prevalence of $H$. pylori infection was examined by biopsy. The relationship between BMI and $H$. pylori infection was analyzed.

Results: $51.8 \%$ of the cases in our population were positive for $H$. pylori infection. On histopathological examination, acute and chronic inflammation findings were higher in $H$. pylori-positive cases compared to $H$. pylori-negative cases. The prevalence of $H$. pylori infection was higher in patients with high BMI than those with low BMI. Statistical analysis showed a significant relationship between BMI and the prevalence of $H$. pylori infection $(\mathrm{p}<0.001)$, and there was a positive linear correlation between these two parameters $(\mathrm{r}=0.542)$. When the risk factors were examined univariable, BMI was found to be a significant risk factor for $H$. pylori infection ( $\mathrm{p}=0.008)$. Multivariable analysis results revealed that $\mathrm{BMI}$ is an independent risk factor for $H$. pylori infection. (OR=1.32 (1.09-3.46), $\mathrm{p}=0.025)$.

Conclusion: Our results showed that there is a significant relationship between BMI and H. pylori infection, and high BMI is an independent risk factor for $H$. pylori infection.
\end{abstract}

Keywords: Body-mass index, gastritis, Helicobacter pylori, histopathological findings 


\section{GİRIŞ}

Helicobacter pylori (H. pylori), dünya nüfusunun yaklaşı yarısını etkileyen Gram-negatif bir bakteridir (1). H. pylori enfeksiyonuna zemin hazırlayan faktörler kesin olarak bilinmemekle beraber sosyoekonomik durumun ters orantılı olarak önemli bir belirleyici olduğu gösterilmiştir $(1,2)$. H. pylori enfeksiyonu birçok hastalık (kronik gastrit, peptik ülser, mide kanseri, mukozayla ilişkili lenfoid doku lenfoması) için risk faktörü olup $(2,3)$ birçok hastalık üzerindeki rolü de (kardiyovasküler, nörolojik, hematolojik ve metabolik hastalıklar) araştırılmaktadır (3).

Obezite dünya genelinde en önemi sağlık sorunlarından biri olup hipertansiyon, diabetes mellitus, uyku apnesi, hipoventilasyon, kardiyovasküler hastalıklar, gastrointestinal hastalıklar ve birçok kanser türünün altında yatan etkenlerden biri olarak kabul edilmektedir (4). Son 20 yılda dünya genelinde obezite görülme sıklığı hızla artmış olup bu artış en çok zengin ülkelerde görülmüştür $(5,6)$. Obezitenin nedenleri arasında genetik ve çevresel çok sayıda sebep sıralanmakla beraber aşırı kalori alımının ve azalan fiziksel aktivitenin merkezi bir rol oynadığ 1 varsayılmaktadır $(5,6)$. Obezitenin değerlendirmesinde dünya genelinde en kabul gören yöntem vücut-kitle indeksi (VKİ'dir.

Literatürde artmış VKİ ile $H$. pylori enfeksiyonu arasında pozitif bir ilişki olduğu öne sürülmüş olup, VKİ’si artan bireylerin daha yüksek bir $H$. pylori enfeksiyonu prevalansına sahip oldukları gözlemlenmiştir $(7,8)$. Ayrıca, VKİ'si artan bireylerde $H$. pylori enfeksiyon tedavisine cevabın daha düşük olduğu bildirilmiştir $(7,8)$. VKİ ile $H$. pylori enfeksiyonu arasındaki bu pozitif ilişki, obezitenin karakteristik bir özelliği olan insülin direncinin $H$. pylori enfeksiyonu ile pozitif olarak ilişkili olduğu görüşünü desteklemektedir (8). Diğer taraftan, bazı çalışmalar obezite ile $H$. pylori pozitifliği arasında ters bir ilişki olduğunu ve $H$. pylori nin ortadan kaldırılmasının VKİde belirgin bir artışa yol açtığını bildirmiştir $(8,9)$.

Literatürdeki bu farklı sonuçlar $H$. pylori ile VKI arasındaki ilişkinin ve altta yatan mekanizmaların netleştirilmesinde daha fazla çalışmaya ihtiyaç olduğunu göstermektedir. Biz burada histopatolojik parametreleri kullanarak $H$. pylori ve VKİ arasındaki ilişkiyi analiz ettik.

\section{GEREÇ VE YÖNTEM}

\section{Etik Onay}

$\mathrm{Bu}$ çalışma için Tekirdağ Namık Kemal Üniversitesi Girişimsel Olmayan Klinik Araştırmalar Etik Kurulu'ndan onay alınmıştır (Tarih: 13.04.2021, Karar No: 2021.89.04.07). Çalışmamız sırasındaki tüm uygulamalarda 1964 Helsinki Bildirgesi'nin ve ulusal/kurumsal bilimsel araştırma komitelerinin etik standartlarına uygun hareket edildi.

\section{Verilerin Toplanması}

Çalışmamı Tekirdağ Namık Kemal Üniversitesi Tip Fakültesi Genel Cerrahi Anabilim Dalinnda gerçekleştirildi. Hastanemizde 2019 yll içerisinde H. pylori için endoskopik biyopsi yapılan tüm hastalar $(\mathrm{n}=1600)$ çalışmaya dahil edildi. Olgulara ait klinik ve histopatolojik bilgiler arşiv kayıtlarından not edildi. Değerlendirmeye alınan parametreler şunlardı: yaş, cinsiyet, kilo, VKİ, alkol öyküsü, sigara öyküsü, ilaç öyküsü, $H$. pylori varlı̆̆ı, intestinal metaplazi varlı̆̆ı, atrofi varlığı, akut ve kronik inflamasyon varlığı. VKİ $<18$ olan olgular grup 1 (zayıf), VKİ'si 18-24,9 arasinda olanlar grup 2 (normal), VKİ’si 25-29,9 arasinda olanlar grup 3 (fazla kilolu), VKİ $>30$ olan olgular ise grup 4 (obez) olarak ele alındı.

\section{Histopatoloji}

Fakültemizde biyopsi örneklerinin değerlendirilmesi geleneksel 1şık mikroskopu (Nikon Eclipse E600, Nikon AG Instruments, İsviçre) kullanılarak deneyimli patologlar tarafından yapılmaktadır. Gastrit parametreleri tanımlanırken genel olarak hasta başına bir adet hematoksilen-eozin lamı ve bir adet Giemsa lamı olmak üzere toplam iki adet lam kesilir ve bu lamlar üzerinden yukarıda bahsedilen beş histopatolojik parametre değerlendirilir. Bu parameterler kalitatif ve subjektif olarak hafif, orta ve ağır olmak üzere üç gruba ayrilır (Şekil 1).

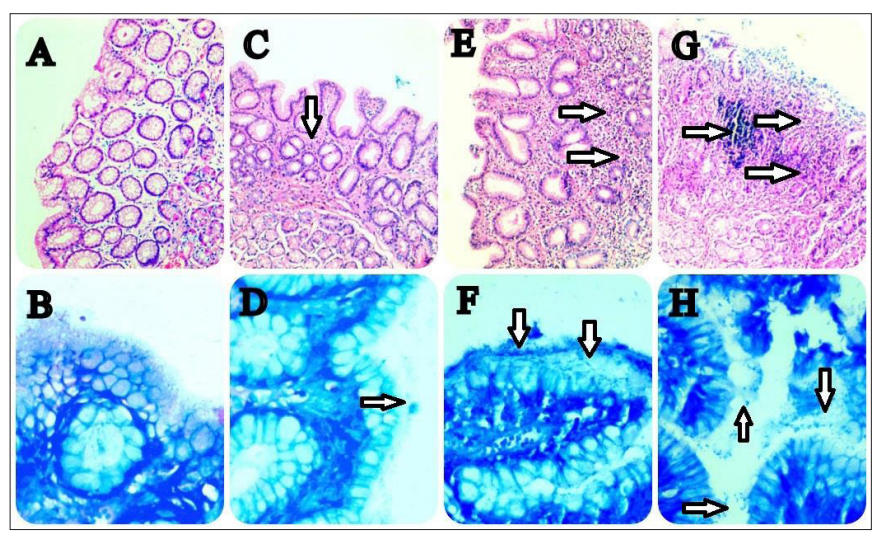

Şekil 1. Gastrit parametreleri açısından akut inflamasyon, kronik inflamasyon, intestinal metaplazi ve atrofi varlığı değerlendirildi. A-B: Grup l'de genel olarak midede gastrit parametreleri (A:H\&E, x10) ve H. pylori (B: Giemsa, x40) izlenmedi. C-D: Grup 2'de genel olarak hafif şiddette gastrit parametreleri (C:H\&E, x10) ve H. pylori (D: Giemsa, x40) mevcuttu (oklar). E-F: Grup 3'de genel olarak orta şiddette gastrit parametreleri (E:H\&E, x10) ve H. pylori (F: Giemsa, x40) mevcuttu (oklar). G-H: Grup 4'de genel olarak ağır şiddette gastrit parametreleri (G:H\&E, x10) ve H. pylori (H: Giemsa, x40) mevcuttu (oklar).

\section{İstatistiksel Analiz}

İstatistiksel analiz için SPSS version 20.0 yazılımı (SPSS Inc., Chicago, ABD) kullanıldı. Tanımlayıcı veriler not edilirken medyan (min-maks), frekans ve yüzde tercih edildi. Kategorik değişkenleri karşılaştırmak için Ki-kare testi kullanıldı ve $\mathrm{p}<0,05$ olan değerler istatistiksel olarak anlamlı kabul edildi. Tek değişkenli ve çok değişkenli risk incelemesi, referans olarak \%95 güven aralığ ve 1,0 risk oranı (OR) olmak üzere lojistik regresyon analizi ile değerlendirildi. 


\section{BULGULAR}

\section{Genel Özellikler}

Olguların $990(\% 61,8)$ 'i erkek, $610(\% 38,2)$ 'u kadındı. Vakaların ortalama yaşı 37 (16-88), ortalama boyu 167,9 (150-195) cm, ortalama kilosu 67,5 (44-117) kg, ortalama VKİ'si 22,9 (14,0-37,3) idi. VKİ’nin yüksek olduğu olgular daha çok erkek $(\% 75,4)$ ve 40 yaşın üzerindeki $(\% 68,7)$ hastalar idi. VKİ açısından vakaları $80(\% 0,05)$ 'inin grup 1; $910(\% 56,8)$ 'unun grup 2, $350(\% 21,8)$ 'sinin grup 3, 260 $(\% 16,2)$ 'ının ise grup 4 olduğu tespit edildi. VKİ’nin yüksek oluğu olgularda dispepsi şikayetleri $(\% 74,3)$, kronik aktif gastrit bulguasu $(\% 70,8), H$. pylori enfeksiyonu $(\% 72,5)$ ile akut inflamasyon $(\% 73,6)$ ve kronik inflamasyon $(\% 68,4)$ bu bulguları daha yüksek oranda mevcut idi. Olguların $830(\% 51,8)$ 'u $H$. pylori açısından pozitif idi. Vakaların $540(\% 33,7)$ 'inda sigara, $70(\% 0,04)$ 'inde alkol kullanımı hikayesi mevcut idi.

\section{VKİ ve H. pylori Enfeksiyonu Arasındaki İlişki}

H. pylori-pozitif katılımcilar $(20,3), H$. pylori-negatif katılımcılara kıyasla daha yüksek $(24,7)$ bir VKİ'ye sahipti. Tüm katılımcılar VKI'lerine göre yukarıda izah edildiği gibi zayıf, normal, fazla kilolu ve obez olmak üzere dört gruba ayrildı. Bu gruplar arasinda $H$. pylori enfeksiyonun prevalansı incelendiğinde zayıf $(\% 37,3)$ ile normal $(\% 43,6)$ olgulara kıyasla yaygınlık, fazla kilolu olgularda daha yüksek $(\% 45,8)$ 'ti ve obez olgularda yaygınlık en yüksek $(\% 50,7)$ seviyeye ulaşıyordu. H. pylori ile mevcut parametreler arasındaki ilişki istatistiksel incelendiğinde H. pylori enfeksiyonunun VKİ $(\mathrm{p}<0.001)$ ile anlaml olarak ilişkili olduğu görüldü (Tablo 1). Ayrıca H. pylori pozitifliği ile yüksek VKİ arasında pozitif bir doğrusal korelasyon mevcut idi $(\mathrm{r}=0,542)$ (Tablo 2).

\begin{tabular}{|c|c|c|c|c|}
\hline & & $\begin{array}{c}\text { H. pylori } \\
\text { pozitif (\%) }\end{array}$ & $\begin{array}{c}\text { H. pylori } \\
\text { negatif (\%) }\end{array}$ & p değeri \\
\hline \multirow{2}{*}{ Yaş } & $>37$ & $477(57,4)$ & $454(58,9)$ & \multirow{2}{*}{0,545} \\
\hline & $\leq 37$ & $353(42,6)$ & $316(41,1)$ & \\
\hline \multirow{2}{*}{ Cinsiyet } & Kadın & $332(40,0)$ & $278(36,1)$ & \multirow{2}{*}{0,108} \\
\hline & Erkek & $498(60,0)$ & $492(63,9)$ & \\
\hline \multirow{2}{*}{ Kilo } & $>67$ & $492(59,2)$ & $439(57,0)$ & \multirow{2}{*}{0,358} \\
\hline & $\leq 67$ & $338(40,8)$ & $331(43,0)$ & \\
\hline \multirow{2}{*}{ Vücut-kitle indeksi } & $1-2$ & $553(66,6)$ & $437(56,7)$ & \multirow{2}{*}{$<0,001$} \\
\hline & $3-4$ & $277(33,4)$ & $333(43,3)$ & \\
\hline \multirow{2}{*}{ Alkol } & Yok & $798(96,1)$ & $732(95,0)$ & \multirow{2}{*}{0,291} \\
\hline & Var & $32(3,9)$ & $38(5,0)$ & \\
\hline \multirow{2}{*}{ Sigara } & Yok & $543(65,4)$ & $517(67,1)$ & \multirow{2}{*}{0,466} \\
\hline & Var & $287(34,6)$ & $253(32,9)$ & \\
\hline \multirow{2}{*}{ İlaç } & Yok & $735(88,5)$ & $665(86,3)$ & \multirow{2}{*}{0,185} \\
\hline & Var & $95(11,5)$ & $105(13,7)$ & \\
\hline \multirow{2}{*}{$\begin{array}{l}\text { İntestinal } \\
\text { metaplazi varlığ } 1\end{array}$} & Yok & $764(92,0)$ & $719(93,3)$ & \multirow{2}{*}{0,307} \\
\hline & Var & $66(8,0)$ & $51(6,7)$ & \\
\hline \multirow{2}{*}{ Atrofi varlığ 1} & Yok & $776(93,4)$ & $728(94,5)$ & \multirow{2}{*}{0,376} \\
\hline & Var & $54(6,6)$ & $42(5,5)$ & \\
\hline \multirow{2}{*}{$\begin{array}{l}\text { Akut inflamasyon } \\
\text { varlığ }\end{array}$} & Yok & $565(68,0)$ & $434(56,3)$ & \multirow{2}{*}{$<0,001$} \\
\hline & Var & $265(32,0)$ & $336(43,7)$ & \\
\hline \multirow{2}{*}{$\begin{array}{l}\text { Kronik } \\
\text { inflamasyon varlığ } 1\end{array}$} & Yok & $549(66,1)$ & $425(55,1)$ & \multirow{2}{*}{$<0,001$} \\
\hline & Var & $281(33,9)$ & $345(44,9)$ & \\
\hline
\end{tabular}

Tablo 2. H. pylori ile klinikopatolojik parametreler arasındaki korelasyon

\begin{tabular}{|lcc|}
\hline & $\begin{array}{c}\text { Korelasyon (\%95 CI) } \\
\text { H. pylori }\end{array}$ & p value \\
\hline Vücut-kitle indeksi & $\mathrm{r}=0,542(0,375-0,732)$ & $\mathrm{p}<0,001$ \\
Akut inflamasyon varlığ & $\mathrm{r}=0,452(0,351-0,691)$ & $\mathrm{p}<0,001$ \\
Kronik inflamasyon varlığ 1 & $\mathrm{r}=0,416(0,338-0,656)$ & $\mathrm{p}<0,001$ \\
\hline Anlamllık sinırı $<<0,05$ olarak kabul edildi. Kısaltmalar: CI: Confidence interva \\
\hline
\end{tabular}

\section{H. pylori Enfeksiyonu İçin Risk Faktörü Analizi}

Tek değişkenli analiz $H$. pylori enfeksyonun VKI $(\mathrm{p}=0,008)$, akut inflamasyon $(\mathrm{p}=0,015)$ ve kronik inflamasyon $(\mathrm{p}=0,028)$ olmak üzere üç parametre ile anlamlı olarak ilişkili olduğunu gösterdi. Çok değişkenli analiz yapıldığında VKİ ve $H$. pylori enfeksyonu için bağımsız bir risk faktörü olduğu tespit edildi $(\mathrm{OR}=1,32$ $(1,09-3,46), \mathrm{p}=0,025)$. Tespit edilen diğer bağımsız risk faktörü ise akut inflamasyon varlığı idi (Tablo 3).

\begin{tabular}{|lccc|}
\hline Tablo 3. H. pylori için risk analizi & & & \\
& $\begin{array}{c}\text { Univariable } \\
\text { analizi }\end{array}$ & \multicolumn{2}{c|}{$\begin{array}{c}\text { Multivariable } \\
\text { analizi }\end{array}$} \\
& $\begin{array}{c}\text { P } \\
\text { değeri }\end{array}$ & $\begin{array}{c}\text { OR } \\
(\mathbf{9 5 \%} \text { CI) }\end{array}$ & $\begin{array}{c}\text { P } \\
\text { değeri }\end{array}$ \\
\hline Vücut-kitle indeksi & 0,008 & $\begin{array}{c}1,32 \\
(1,09-3,46)\end{array}$ & 0,025 \\
Akut inflamasyon varlığ & 0,015 & $\begin{array}{c}1,43 \\
(1,12-4,27)\end{array}$ & 0,043 \\
Kronik inflamasyon varlığ 1 & 0,028 & $\begin{array}{c}2,53 \\
(0,95-4,71)\end{array}$ & 0,084 \\
\hline
\end{tabular}

Anlamlılık sınırı $\mathrm{p}<0,05$ olarak kabul edildi. Çalışmadaki önemli sonuçlar italik olarak not edildi. Kisaltmalar: OR: Odds ratio, CI: Confidence interval

\section{TARTIŞMA}

$\mathrm{Bu}$ çalışmada VKİ ile $H$. pylori enfeksiyonu arasındaki ilişkiyi inceledik ve $H$. pylori enfeksiyonu için VKİ’nin bağımsız bir risk faktörü olduğunu gördük. Ayrıca $H$. pylori enfeksiyonu akut ve kronik inflamasyonla da anlamlı olarak ilişkili idi.

H. pylori enfeksiyonu, hem mide hem de mide dişı hastalıklara neden olabilen dünya genelinde en yaygın kronik enfeksiyondur (1). Ülkeler arasında prevalansı değişmekte olan $H$. pylori enfeksiyonu, kronik gastrit, peptik ülser, MALT lenfoma gibi hastalıkların ana etkeni olduğu gibi, kardiyovasküler hastalık, diyabet ve non-alkolik hepatit gibi hastalıklar ile de ilişkili olduğu bildirilmektedir (1-3). H. pylorinin mide asidinden etkilenmeden geçebilmesi üreaz aktivitesinin bir sonucudur. Bu etki şu şekilde özetlenebilir. Bakteri üreyi hidrolize ederken amonyak ve karbondioksit oluşturur (10). Amonyak $\mathrm{H}_{2} \mathrm{O}$ ile birleşip amonyuma dönüşürken çevresini alkalileştirir ve bu durum bakteriyi mide asidinin zararlı etkisinden korur $(10,11)$. Daha sonra bakteri salgıladığı çeşitli enzimler sayesinde mukusu parçalayarak epitel yüzeyinde hasar yapar (11). Ayrıca epitel hücrelerinin arasında kolonize olur ve mide mukozasına invaze olmadan inflamasyon yapar $(11,12)$. 
Ek olarak bakteri trombosit aktive edici faktör (PAF) salgılar, mukozaya nötrofil ve monosit toplanmasını sağlar (12). Ve sonuçta kronik aktif gastrit tablosu meydana gelir. Çalışmamızda da H. pylori enfeksiyonu olan olgularda kronik aktif gastrit bulgusu belirgin olarak yüksek izlenmiştir.

H. pylori ile enfekte kişilerde aynı semptom ve hastalık görülmeyebilir. Bir kısım olgularda asemptomatik gastrit görülürken, bir kısmında ise duodenal ve gastrik ülser veya MALT lenfoma gibi ciddi hastalıklar görülebilir $(13,14)$. Örneğin bazı hatsaklarda $H$. pylori enfeksiyonu mide mukozasında kronik enflamasyona bağlı mide glandüler hücrelerinin kaybı ile sonuçlanan kronik atrofik gastrite sebep olarak mide kanseri için önemli bir risk faktürü oluşturur $(14,15)$. Ayrıca bakterinin virulan suşları (cagA ve vacA pozitif) ile ülser, atrofik gastrit ve mide kanseri arasındaki anlamlı bir ilişki mevcuttur (15). H. pylori genotipleri ile ilgili araştırma çalışmamızın kapsamı dışında olmakla beraber bu konudaki ileri çalışmaların artmasıyla enfekte kişilerin hangi hastalık riski ile karşı karşıya olduğunun daha da iyi anlaşılacağını düşünmekteyiz.

Literatürde VKİ ile H. pylori enfeksiyonu arasındaki ilişki tartışmalıdır. Bazı çalışmalar H. pylori enfeksiyonunun obez hastalarda daha yaygin olma eğiliminde olduğunu ve fazla kilolu bireylerde $H$. pylori enfeksiyonunun önemli ölçüde daha düşük eradikasyon eğilimi gösterdiğini bildirmektedir (16-18). Diğer çalışmalarda ise obezite ile $H$. pylori enfeksiyonunun ters orantılı olduğunu ve $H$. pylorỉnin ortadan kaldırılmasının belirgin bir VKİ artışına yol açabileceğini tarif etmektedir $(19,20)$. Artmış VKİ’nin, immün sistem üzerindeki etkileri birçok çalışmada araştırılmış olup birçok çalışmada morbid obez hastalarda polimorfonükleer hücrelerdeki bakterisidal kapasitenin ve monositlerin makrofajlara olgunlaşmasının azaldığ gösterilmiştir (21-23). Örneğin Moulin ve ark. (22) aynı yaş ve cinsiyetteki sağlıklı bireylere kıyasla şiddetli obez hastalarda inflamatuvar hücrelerdeki öldürücü hücre aktivitede önemli bir azalma olduğunu bildirmiştir. Obez bireylerde gözlenen bu bağışılılı değişiklikleri, H. pylori enfeksiyonu için daha elverişli bir bağışıklık ortamı oluşturabilir. Nitekim Perdichizzi ve ark. (24) $H$. pylori enfeksiyonunun hiperglisemik obez kişilerde artma eğiliminde olduğunu göstermiştir.

Bazı çalışmalarda ise $H$. pylorìnin eradike edilmesinin gastrik leptin ekspresyonunu azalttığ ve bu azalmanın VKİde bir artışa sebep olduğu bildirilmiştir (27-29). Örneğin Osawa ve ark. (27) H. pylori eradikasyonundan sonra mide dokusunda iştahla ilgi hormon olan grelin konsantrasyonunun önemli ölçüde arttığını göstermiştir. Furuta ve ark. (28) ise $H$. pylori tedavisi gören hastaların kilo aldığını belgelemiştir. Ayrıca literatürde, H. pylori enfeksiyonun bazı interlökinleri ve proinflamatuvar sitokinlerin (örneğin, TNFa) aşırı salınımını uyardığı, bu mediatörlerin salınımının kronik insülin direncinin ve lipid dismetabolizmasının daha da kötüleşmesine yol açtı̆̆ 1 ve bu durumun da obezitenin ortaya çıkmasına katkı sağladığı bildirilmiştir $(25,26)$.

Üstelik literatürdeki bazı çalışmalar vücut ağırlığı ile H. pylori prevalansında herhangi bir ilişki olmadığını bildirmiştir. Örneğin Kawano ve ark. (30) yaptığ 1 çalışmada asemptomatik kişilerde $H$. pylori enfeksiyonu ile VKİ arasında herhangi bir ilişkili bulamamıştır. Dahası Blaser ve ark. (31) çalışmalarında $H$. pylori'nin neden olduğu mide enflamasyonunun grelin gibi birtakım bağırsak hormonlarının daha az salgılanmasına sebep olduğunu, ve bu nedenle erken çocukluk döneminde $H$. pylori’ye maruz kalan bireylerde iştah ve yiyecek alımında azalma olduğunu tespit etmişlerdir.

Literatürde görülen bu birbirinden farklı sonuçların sebebi olarak kullanılan yöntemlerin farklılığı, araştırma yapılan popülasyonların çeşitliliği ve çalışmaya dahil edilen hasta sayısı gibi faktörler sıralanabilir. Çalışmamızda daha yüksek VKİ'li bireylerin H. pylori enfeksiyonu açısından pozitif olma olasılığının daha yüksek olduğunu gösterdik. Sonuçlarımıza göre yüksek VKİ H. pylori enfeksiyonu için zemin hazırlayan bir faktördür. Ancak literatürde birbiriyle çelişen birçok çalışma mevcut olması nedeniyle bu bulgunun daha geniş çalışmalar ile desteklenmesi gerekmektedir.

Çalışmamızın kısıtlılıkları arasında katılımcı sayısının düşük olması, sağlıklı gönüllülerden oluşan bir kontrol grubunun olmamasi, $H$. pylori genotiplerinin çalışılmaması, metabolik belirteç seviyelerinin tespit edilmemesi sayllabilir.

\section{SONUÇ}

Çalışmamız, VKİnin $H$. pylori enfeksiyonu ile anlamlı olarak ilişkili olduğunu ve VKİnin artışının H. pylori enfeksiyonu için bağımsız bir riski faktörü olduğunu göstermekte olup bu ilişkinin altında yatan mekanizmaların daha net olarak açıklığa çıkarılması, hastalığın tedavisi ve önlenmesinde daha başarılı yöntemlere ışık tutabilir.

\section{ETİK BEYANLAR}

Etik Kurul Onayı: Bu çalışma için Tekirdağ Namık Kemal Üniversitesi Girişimsel Olmayan Klinik Araştırmalar Etik Kurulu'ndan onay alınmıştır (Tarih: 13.04.2021, Karar No: 2021.89.04.07).

Aydınlatılmış Onam: Çalışma retrospektif olarak dizayn edildiği için hastalardan aydınlatılmış onam alınmamıştır. 
Hakem Değerlendirme Süreci: Harici çift kör hakem değerlendirmesi.

Çıkar Çatışması Durumu: Yazarlar bu çalışmada herhangi bir çıkara dayalı ilişki olmadığını beyan etmişlerdir.

Finansal Destek: Yazarlar bu çalışmada finansal destek almadıklarını beyan etmişlerdir.

Yazar Katkıları: Yazarların tümü; makalenin tasarımına, yürütülmesine, analizine katıldığını ve son sürümünü onayladıklarını beyan etmişlerdir.

\section{KAYNAKLAR}

1. Lorenzo I, Fernández-de-Larrea N, Michel A, et al. Helicobacter pylori seroprevalence in Spain: influence of adult and childhood sociodemographic factors. Eur J Cancer Prev 2019; 28: 294-303

2. Krueger WS, Hilborn ED, Converse RR, Wade TJ. Environmental risk factors associated with Helicobacter pylori seroprevalence in the United States: a cross-sectional analysis of NHANES data. Epidemiol Infect 2015; 143: 2520-31.

3. Kaplan M, Tanoglu A, Duzenli T, et al. Helicobacter pylori treatment in Turkey: Current status and rational treatment options. North Clin Istanb 2019; 7: 87-94.

4. Caballero B. Humans against Obesity: Who Will Win? Adv Nutr 2019; 10: 4-9.

5. Albuquerque D, Nóbrega C, Manco L, et al. The contribution of genetics and environment to obesity. Br Med Bull 2017; 123: 15973.

6. Zhang Y, Du T, Chen X, et al. Association between Helicobacter pylori infection and overweight or obesity in a Chinese population. J Infect Dev Ctries 2015; 9: 945-3.

7. Siddiqui B, Yakoob J, Abbas Z, et al. Distribution of Helicobacter pylori infection and abnormal body- mass index (BMI) in a developing country. J Infect Dev Ctries 2018; 12: 342-6.

8. Suki M, Leibovici Weissman Y, Boltin D, et al. Helicobacter pylori infection is positively associated with an increased BMI, irrespective of socioeconomic status and other confounders: a cohort study. Eur J Gastroenterol Hepatol 2018; 30: 143-8.

9. Hamada M, Nomura R, Ogaya Y, et al. Potential involvement of Helicobacter pylori from oral specimens in overweight body-mass index. Sci Rep 2019; 9: 4845.

10. Kamboj AK, Cotter TG, Oxentenko AS. Helicobacter pylori: the past, present, and future in management. Mayo Clin Proc 2017; 92: 599-604.

11. Mentis A, Lehours P, Mégraud F. Epidemiology and diagnosis of Helicobacter pylori infection. Helicobacter 2015; 20: 1-7.

12. Eusebi LH, Zagari RM, Bazzoli F. Epidemiology of Helicobacter pylori infection. Helicobacter 2014; 19: 1-5

13. Mitchell H, Katelaris P. Epidemiology, clinical impacts and current clinical management of Helicobacter pylori infection. Med J Aust 2016; 204: 376-80.

14.Peng C, Li NS, Hu Y, Lu NH. Impact factors that modulate gastric cancer risk in Helicobacter pylori-infected rodent models. Helicobacter 2019; 24: e12580.

15. Munoz-Ramirez ZY, Mendez-Tenorio A, Kato I, et al. Whole genome sequence and phylogenetic analysis show Helicobacter pylori strains from Latin America have followed a unique evolution pathway. Front Cell Infect Microbiol 2017; 7: 50.

16. Polyzos SA, Kountouras J, Zavos C, et al. The association between Helicobacter pylori infection and insulin resistance: a systematic review. Helicobacter 2011; 16: 79-88.
17. Renshaw AA, Rabaza JR, Gonzalez AM, et al. Helicobacter pylori infection in patients undergoing gastric bypass surgery for morbid obesity. Obes Surg 2001; 11: 281-3.

18. Arslan E, Atilgan H, Yavasoglu I. The prevalence of Helicobacter pylori in obese subjects. Eur J Intern Med 2009; 20: 695-7.

19. Lane JA, Murray LJ, Harvey IM, et al. Randomised clinical trial: Helicobacter pylori eradication is associated with a significantly increased body mass index in a placebo-controlled study. Aliment Pharmacol Ther 2011; 33: 922-9.

20. Yang YJ, Sheu BS, Chang WL, et al. Increased body mass index after $H$. pylori eradication for duodenal ulcer predisposes to erosive reflux esophagitis. J Clin Gastroenterol 2009; 43: 705-10.

21. Marti A, Marcos A, Martinez JA. Obesity and immune function relationships. Obes Rev 2001; 2: 131-40.

22. Moulin CM, Marguti I, Peron JP, et al. Impact of adiposity on immunological parameters. Arq Bras Endocrinol Metabol 2009; 53: 183-9.

23. Krishnan EC, Trost L, Aarons S, et al. Study of function and maturation of monocytes in morbidly obese individuals. J Surg Res 1982; 33: 89-97.

24.Perdichizzi G, Bottari M, Pallio S, et al. Gastric infection by Helicobacter pylori and antral gastritis in hyperglycemic obese and in diabetic subjects. New Microbiol 1996; 19: 149-54.

25. Glass CK, Olefsky JM. Inflammation and lipid signaling in the etiology of insulin resistance. Cell Metab 2012; 15: 635-45.

26. Basso D, Plebani M, Kusters JG. Pathogenesis of Helicobacter pylori infection. Helicobacter 2010; 15: 14-20.

27. Osawa H, Nakazato M, Date Y, et al. Impaired production of gastric ghrelin in chronic gastritis associated with Helicobacter pylori. J Clin Endocrinol Metab 2005; 90: 10-6.

28. Furuta T, Shirai N, Xiao F, et al. Effect of Helicobacter pylori infection and its eradication on nutrition. Aliment Pharmacol Ther 2002; 16799-806.

29. Roper J, Francois F, Shue PL, et al. Leptin and ghrelin in relation to Helicobacter pylori status in adult males. J Clin Endocrinol Metab 2008; 93: 2350-7.

30. Kawano S, Kawahara A, Nakai R, et al. Helicobacter pylori infection does not affect serum leptin concentration and body mass index. J Gastroenterol 2001; 36579-80.

31. Blaser MJ, Atherton JC. Helicobacter pylori persistence: biology and disease. J Clin Invest 2004; 113321-33. 